\title{
AVALIAÇÃO DA BRIGADA DE INCÊNDIOS FLORESTAIS DO PARQUE NACIONAL DAS SEMPRE-VIVAS, MG
}

\author{
Luciana Coelho de Moura ${ }^{1}$ \\ ${ }^{1}$ Engenheira Florestal, Doutoranda em Ciência Florestal na Universidade Federal de \\ Viçosa - UFV lucianacm2005@yahoo.com.br \\ Recebido em: 08/04/2016 - Aprovado em: 30/05/2016 - Publicado em: 20/06/2016 \\ DOI: 10.18677/Enciclopedia_Biosfera_2016_155
}

\begin{abstract}
RESUMO
O objetivo do trabalho foi avaliar a brigada de combate aos incêndios florestais do Parque nacional das Sempre-Vivas, MG. Aplicaram-se questionários à todos os membros da brigada e foram observados os equipamentos de combate e de proteção individual utilizados pelos brigadistas. A brigada de incêndios florestais do Parque Nacional das Sempre-Vivas apresenta bom nível de treinamento e está tecnicamente preparada e protegida para combater pequenos focos de incêndio. Todos os brigadistas compreendem a importância de trabalhos preventivos e a vigilância é o principal método a fim de se evitar a entrada do fogo na unidade de conservação. O grande nível de satisfação tanto em trabalhar como brigadista como em relação à coordenação da brigada colabora com a boa realização do trabalho de combate e prevenção a incêndios florestais.
\end{abstract}

PALAVRAS-CHAVE: cerrado, fogo, unidade de conservação.

\section{EVALUATION OF FOREST FIRE BRIGADE OF SEMPRE-VIVAS NATIONAL PARK, MG}

\begin{abstract}
The objective of this study was to evaluate the brigade combat forest fires in Semprevivas National Park, MG. Questionnaires were applied to all members of the brigade and were seen fighting equipment and personal protective equipment used by firefighters. A forest fire brigade of the Sempre-vivas National Park presents a good level of training and is technically protected and prepares to fight small fires. All firefighters understand the importance of preventive efforts and vigilance is the main method in order to prevent the fire entering the protected area. The great satisfaction in working as much as brigadista regarding coordination brigade collaborates with proper execution of the work to combat and prevent forest fires.
\end{abstract}

KEYWORDS: conservation unit, fire, thick.

\section{INTRODUÇÃO}

A ocupação desordenada, a expansão urbana e agropecuária, a exploração irracional e principalmente o uso indiscriminado do fogo têm ameaçado o bioma cerrado, fazendo com que espécies nativas importantes, comercial e ecologicamente, entrem em extinção (FIEDLER et al., 2004).

Algumas características das espécies do cerrado funcionam como estratégias ENCICLOPÉDIA BIOSFERA, Centro Científico Conhecer - Goiânia, v.13 n.23; p. 17942016 
adaptativas ao fogo, como a forte suberização do tronco e dos galhos, o que permite isolamento térmico dos tecidos internos, mesmo em temperaturas elevadas (VALE \& ELIAS, 2014); a presença de frutos mais rústicos, capazes de proteger as sementes (CIRNE \& MIRANDA, 2008), a quebra de dormência e dispersão de sementes (FICHINO et al., 2012); o controle da floração e frutificação do estrato vegetal (PALERMO \& MIRANDA, 2012); e a capacidade de rebrota através da copa, dos rizomas, do caule, da raiz e das estruturas subterrâneas em espécies lenhosas (MEDEIROS \& MIRANDA, 2005).

Contudo, altas freqüências e intensidades de queimadas podem causar efeitos negativos para a vegetação do cerrado, como o baixo crescimento e sobrevivência de espécies lenhosas, cujas conseqüências são a redução na densidade arbórea, o aumento do entouceiramento e a diminuição da diversidade de espécies (SILVA et al., 2011; RIBEIRO et al., 2012; ANDRADE \& MIRANDA, 2014). Em suas pesquisas MEDEIROS \& MIRANDA (2005) verificaram elevadas taxas de mortalidade em campo-sujo e no cerrado sensu stricto após queimadas prescritas.

Em resumo, os incêndios florestais geram diversos prejuízos econômicos e paisagísticos, ecológicos, podendo ocorrer em Unidades de Conservação, áreas de preservação, fazendas, margens de estradas, proximidades de aglomerados urbanos e áreas de reflorestamento, dentre outras localidades (FIEDLER et al., 2006). Apesar de anos de estudo científico e de toda atenção da mídia em relação aos incêndios florestais, os efeitos que estes causam ao ambiente ainda têm sido ignorados (LOURENÇO et al., 2012).

De modo geral, pode-se dizer que o homem é o principal causador dos incêndios florestais. As principais causas dos incêndios florestais no País são devido a: queima para limpeza, que corresponde a $63,7 \%$ da á/rea queimada, seguida da queima criminosa ou provocada por incendiários $(14,7 \%)$; fogos de recreação ou acidental (11,6\%); diversos (4,4\%); fumantes (2,9\%); estradas de ferro $(0,5 \%)$; e queimas de origem natural ou provocadas por raios, que correspondem a apenas 0,2\% (BONFIN et al., 2003).

$\mathrm{Na}$ proteção aos incêndios florestais, uma brigada de incêndios trabalha principalmente em três frentes: prevenção, monitoramento e combate. A melhor forma de combater um incêndio florestal é através da prevenção, e, qualquer ação para prevenção dos incêndios florestais deve buscar a eliminação das causas (NOGUEIRA et al., 2002). Um monitoramento eficiente é a primeira etapa para o sucesso do serviço de combate, pois, quanto mais cedo o foco for detectado menor será a frente do incêndio e, conseqüentemente, menor a estrutura a ser empregada para debelá-lo (NOGUEIRA et al., 2002).

O combate à incêndios florestais normalmente ocorre em situações tensas, já que a própria natureza dessa atividade requer uma atuação de emergência, mesmo quando se usa procedimento para retardar o fogo (FIEDLER, et al., 2015). Assim, a brigada de incêndios deve estar preparada física e psicologicamente, bem como em termos de equipamento de segurança e de combate para proporcionar um trabalho eficiente.

O treinamento adequado da brigada de incêndio melhora a qualidade das ações iniciais de combate aos focos de queimadas, o que evita que o fogo atinja grandes dimensões (SILVA et al., 2003). O controle da qualidade dos equipamentos, ferramentas e máquinas utilizadas pela brigada de incêndio, além de aumentar a eficiência do combate, garante mais segurança individual aos brigadistas (SILVA et al., 2003). 
O objetivo do presente trabalho foi avaliar as condições de trabalho, o nível de treinamento, a satisfação dos funcionários participantes, as condições dos equipamentos e ferramentas utilizadas pelas brigadas de combate aos incêndios florestais do Parque nacional das Sempre-Vivas, MG.

\section{MATERIAL E MÉTODOS}

O trabalho foi realizado no Parque Nacional das Sempre-Vivas no estado de Minas Gerais. O parque foi criado através do Decreto de 13 de dezembro de 2002 protegendo uma área de 124.555 hectares, inserida em quatro municípios do estado de Minas Gerais: Diamantina, Buenópolis, Bocaiúva e Olhos D’água. Segundo o mesmo Decreto, o parque está inserido, em sua totalidade no bioma Cerrado, e geograficamente na Serra do Espinhaço.

.A pesquisa foi realizada em outubro de 2009, na sede da brigada de incêndios do Parque Nacional das Sempre-Vivas, localizada em Macacos (vilarejo que compõe o distrito de São João da Chapada, pertencente ao município de Diamantina-MG).

A brigada de combate à incêndios florestais do Parque Nacional das SempreVivas é temporária, sendo que os brigadistas são contratados por um período de seis meses, julho a dezembro, por ser esse o período em que mais ocorrem focos de calor, principalmente no meses de junho a outubro (Tabelas 1 e 2). A brigada de incêndios do Parque Nacional das Sempre-Vivas é formada por 20 brigadistas, que possuem escala de trabalho de sete dias seguidos de outros sete dias de descanso, e um coordenador.

A pesquisa foi realizada através da aplicação de um questionário (Anexo 1) ao coordenador da brigada e a 16 membros da brigada de incêndios presentes no dia da pesquisa. O questionário aplicado foi proposto por SILVA et al. (2003) (Anexo 1) e teve como objetivo levantar informações sobre as condições de atuação, o nível de motivação e treinamento dos brigadistas e quais as práticas de prevenção que têm sido mais usadas dentro de cada área. Foi realizado ainda o registro fotográfico dos equipamentos de combate e de proteção individual utilizados pela brigada de incêndios.

TABELA 1 - Números mensais de focos de incêndio do estado de Minas Gerais, dos anos de 2008 e 2009

\begin{tabular}{ccc}
\hline Mês & 2008 & 2009 \\
\hline Janeiro & 59 & 21 \\
Fevereiro & 31 & 37 \\
Março & 35 & 59 \\
Abril & 38 & 46 \\
Maio & 99 & 95 \\
Junho & 135 & 57 \\
Julho & 212 & 132 \\
Agosto & 421 & 267 \\
Setembro & 1162 & 516 \\
Outubro & 1682 & 632 \\
Novembro & 893 & - \\
Dezembro & 82 & - \\
\hline
\end{tabular}

Fonte: INMET 
TABELA 2 - Número de focos de incêndio, dos meses de junho a outubro, do Parque Nacional das Sempre-Vivas, dos anos de 2008 e 2009

\begin{tabular}{lccc}
\hline & Mês & 2008 & 2009 \\
\hline Junho & 4 & - \\
Julho & 3 & - \\
Agosto & - & 3 \\
Setembro & 3 & 7 \\
Outubro & - & 2 \\
\hline
\end{tabular}

Fonte: SISFOGO

\section{RESULTADOS E DISCUSSÃO}

O tempo médio de participação na brigada é de cinco meses, já que o Parque Nacional das Sempre-Vivas trabalha com brigadas de incêndio temporárias. Dentre os brigadistas entrevistados, $88 \%$ (14/16) se sentem satisfeitos em trabalhar na brigada de incêndios florestais (Figura 1) o que colabora para o grande percentual obtido quando se questionou sobre o preparo para combater pequenos focos de incêndio $(94 \%$ - 15/16) (Figura 1), já que satisfação está diretamente ligada com a boa realização do trabalho. Apenas $50 \%(8 / 16)$ dos brigadistas relataram tem participado de cursos de treinamento oferecidos pelo Corpo de Bombeiros e outras instituições e $88 \%$ (14/16) deles consideraram tais cursos adequados (Figura 1). Em virtude disso, a própria Unidade de Conservação, ofereceu um curso de treinamento para todos os brigadistas, com o intuito de prepará-los melhor para prevenir e combater incêndios florestais.

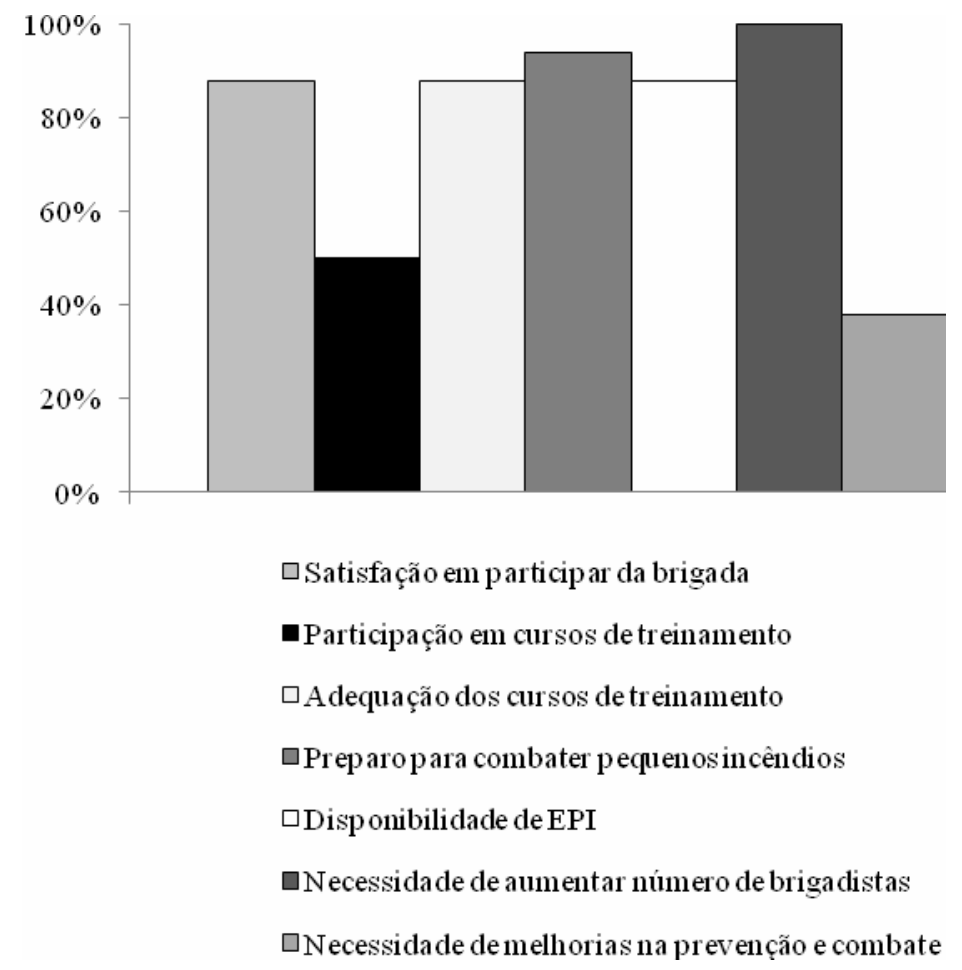

FIGURA 1 - Satisfação em participar da brigada, participação em cursos de treinamento e adequação desses cursos segundo a brigada de incêndios, preparo para combater pequenos focos de incêndios, percentual dos brigadistas que possuem equipamento de proteção individual, necessidade de se aumentar o número de brigadistas e de se melhorar a prevenção e o combate, segundo a brigada de incêndios florestais do Parque Nacional das Sempre-Vivas, MG. 
FIEDLER et al. (2006), analisando a brigada da Fazenda Água Limpa - DF, onde apenas $39,1 \%$ dos entrevistados afirmaram ter recebido treinamento de brigadista, também concluiram que a brigada necessitava de treinamentos complementares ao curso básico oferecido, considerando-se a necessidade constante de reciclagens e o surgimento de novos métodos e tecnologias na área.

Dos brigadistas entrevistados, 81\% (13/16) acreditam haver necessidade de se aumentar o número de brigadistas, e apenas $38 \%(6 / 16)$ acreditam que deve haver melhorias na prevenção e combate (Figura 1). Esses dados refletem que a equipe de brigadistas se considera bem treinada para combater incêndios florestais, porém, principalmente devido a grande extensão do Parque Nacional das SempreVivas, o número de brigadistas é insuficiente para abranger toda a área.

Em relação aos equipamentos de proteção individual, 88\% (14/16) responderam que existe EPI disponível para uso, como pode ser observado na Figura 1 e na Figura 2A. Esse valor é bastante considerável, quando comparado a outras brigadas estudadas por SILVA et al. (2003) como a do Jardim Botânico de Brasília - JBB, que apresentou valor de $40 \%$ para a disponibilidade de EPI, ou a da Fazenda Água Limpa - FAL, onde $75 \%$ dos brigadistas não contam com EPI. Porém, o ideal mesmo é que todos os brigadistas possam fazer uso dos equipamentos de proteção individual, já que estes são extremamente importantes para resguardar a integridade física de quem participa do combate.

Observou-se ainda, boas quantidades de equipamentos de combate, como bombas contais, abafadores, pás, enxadas e ancinhos (Figuras 2B, 2C e 2D).

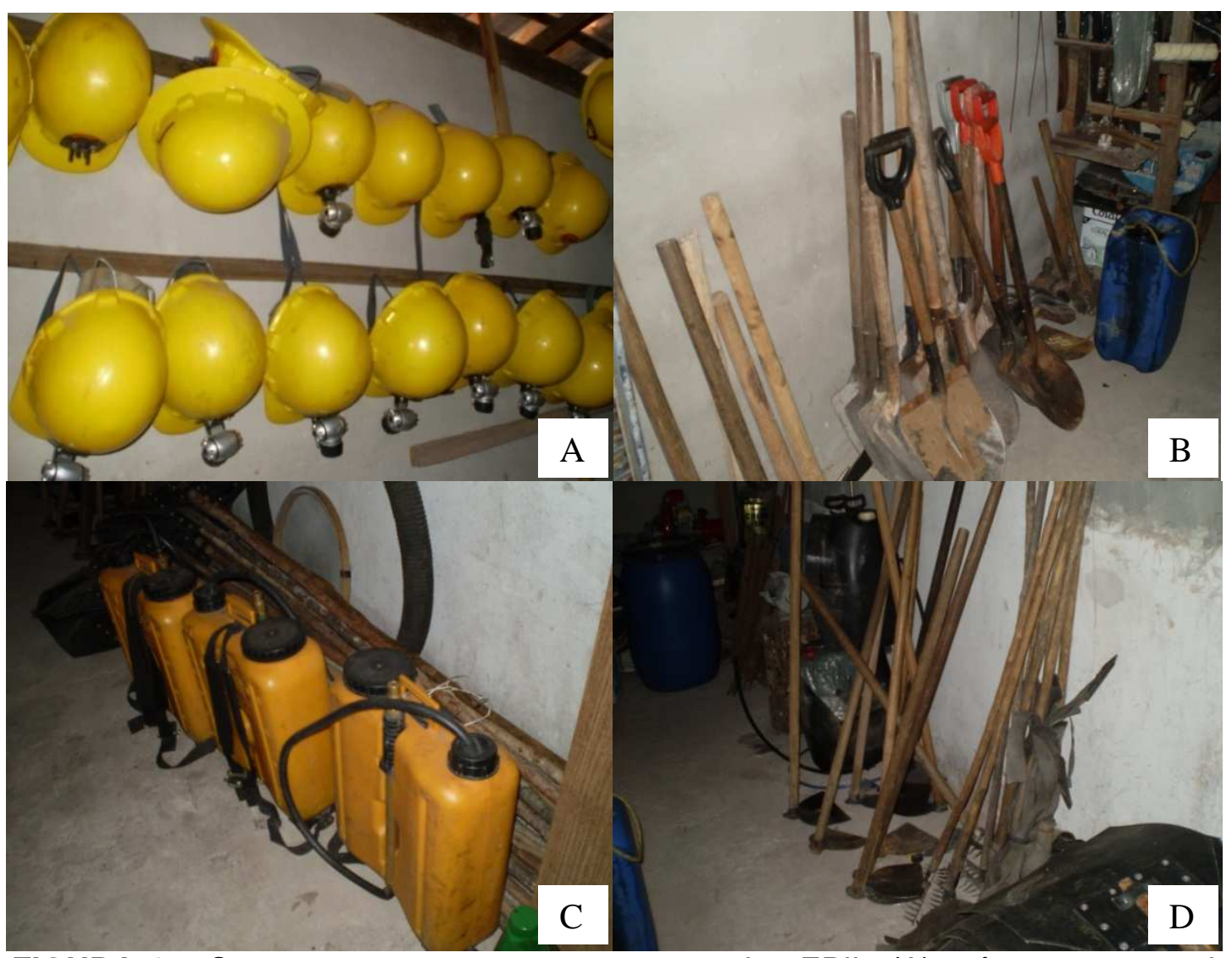

FIGURA 2 - Capacetes noturnos, componentes dos EPI's (A), pás para construir aceiros ou abafar o fogo (B), bombas costais para carregar água (C), enxadas e ancinhos para construir aceiros ou abafar o fogo (D) usados pelos brigadistas do Parque Nacional das Sempre-Vivas, MG. 
Observa-se grande satisfação dos brigadistas quando se questiona sobre a coordenação da brigada de incêndios, já que $50 \%(8 / 16)$ deles a consideram boa e $43,75 \%(7 / 16)$ a consideram ótima (Figura 3).

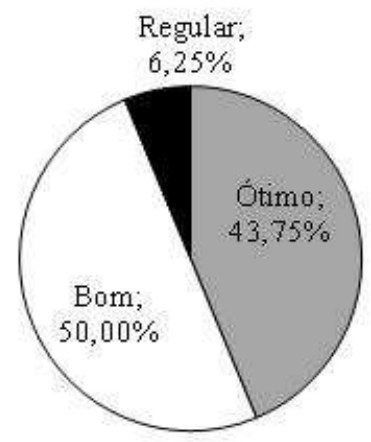

FIGURA 3 - Avaliação da coordenação da brigada em ótima, boa ou ruim, segundo a brigada de incêndios florestais do Parque Nacional das Sempre-Vivas, MG.

No que se refere à prevenção, todos os brigadistas salientaram estar envolvidos com trabalhos preventivos, como vigilância através da ronda diária ou com uso de pontos estratégicos (torre), campanhas educativas como visitações à comunidade do entorno e reuniões, ou ainda através da manutenção de estradas para facilitar a chegada ao foco de incêndio. Na Tabela 3, observa-se a distribuição dessas ações preventivas, onde $90 \%$ dos brigadistas afirmaram que a vigilância é um importante trabalho preventivo realizado pela brigada, sendo que $70 \%$ acreditam que a ronda é o método de vigilância mais eficaz e $20 \%$ afirmam que a torre é o melhor método. Para $15 \%$ dos entrevistados, as campanhas preventivas representam um bom método a fim de se evitar a entrada do fogo na unidade de conservação, e para $10 \%$, a manutenção de estradas é uma ação preventiva importante desenvolvida pela brigada.

TABELA 3 - Atividades preventivas realizadas pela brigada de incêndios florestais do Parque Nacional das SempreVivas, MG.

\begin{tabular}{lll}
\hline \multicolumn{2}{c}{ Atividade Preventiva } & $\%$ \\
\hline \multirow{2}{*}{ Vigilância } & Ronda & 70 \\
\cline { 2 - 3 } & Torre & 20 \\
\hline Campanhas educativas & 15 \\
\hline Manutenção de estradas & 10 \\
\hline
\end{tabular}

Segundo o coordenador da brigada de incêndios do Parque Nacional das Sempre-Vivas, além das atividades preventivas, a ausência do turismo dentro do parque é um fator que colabora para a menor ocorrência de focos de incêndios, já que o parque encontra-se em fase de implantação e desapropriação de antigos 
moradores, permanecendo fechado à visitação pública, e qualquer incursão na área deve ser autorizada pela chefia da unidade em Diamantina, MG. Por outro lado, a permanência de moradores que ainda possuem imóveis rurais dentro da unidade de conservação pode colaborar para o aumento de focos de incêndios, já que estes muitas vezes se recusam à desapropriação e até realizam práticas de queima para reforma de suas pastagens dentro e no entorno do parque.

A utilização de queimadas visando a renovação de pastagens e a limpeza de áreas é em geral realizada sem a mínima preocupação com a segurança, tanto na área a ser queimada quanto no entorno. Neste caso, deve-se considerar os aspectos legais para realização da queima controlada (PORTARIA No 94/98-N, de 9 de julho de 1998, que regulamenta procedimentos referentes a queimadas), além de aspectos como a construção de aceiros, a execução da queima contra o vento e a presença de uma equipe treinada em combate ao fogo em caso de perda do controle da situação (FIEDLER et al., 2004).

De forma geral, o início e a propagação do fogo em áreas florestais podem ser previstos conhecendo-se os fatores humanos, ecológicos e climáticos que participam do processo, como a hidrografia, o uso e cobertura do solo, a geomorfologia e as distâncias às habitações humanas (EUGENIO et al., 2016). Assim, além de atividades de treinamento à brigada de incêndios e de prevenção aos focos de incêndio, atividades educativas e de conscientização de toda a população envolvida devem ser consideradas.

\section{CONCLUSÕES}

- A brigada de incêndios florestais do Parque Nacional das Sempre-Vivas apresenta bom nível de treinamento e está tecnicamente preparada e protegida para combater pequenos focos de incêndio;

- Todos os brigadistas compreendem a importância de trabalhos preventivos e a vigilância é o principal método a fim de se evitar a entrada do fogo na unidade de conservação;

- O grande nível de satisfação tanto em trabalhar como brigadista como em relação à coordenação da brigada colabora com a boa realização do trabalho de combate e prevenção a incêndios florestais.

\section{AGRADECIMENTOS}

Aos funcionários do Parque Nacional das Sempre-Vivas, pela autorização e concepção das entrevistas.

\section{REFERÊNCIAS}

ANDRADE, A. Z.; MIRANDA, H. S. The dynamics of the soil seed bank after a fire event in a woody savanna in central BraziL. Plant Ecology, v. 215, n. 10, p. 1199-1209, 2014. doi: 10.1007/s11258-014-0378-z

BONFIM, V. R.; RIBEIRO, G. A.; SILVA, E.; BRAGA, G. M. Diagnóstico do uso do fogo na entorno do Parque estadual da Serra do Brigadeiro (PESB), MG. Revista Árvore, Viçosa-MG, v.27, n.1, p.87-94, 2003. doi: 10.1590/S010067622003000100001 
EUGENIO, F. C.; SANTOS, A. R.; FIEDLER, N. C.; RIBEIRO, G. A.; SILVA, A. G.; SANTOS, A. B.; PANETO, G. G.; SCHTTIN, V. R. Applying GIS to develop a model for forest fire risk: A case study in Espírito Santo, Brazil. Journal of Environmental Management, v.173, p. 65-71, 2016. doi:10.1016/j.jenvman.2016.02.021

CIRNE, P.; MIRANDA, H. S. Effects of prescribed fires on the survival and release of seeds of Kielmeyera coriacea (Spr.) Mart. (Clusiaceae) in savannas of Central Brazil. Brazilian Journal of Plant Physiology, v.20, n.3, 2008. dx.doi.org/10.1590/S167704202008000300004

FICHINO, B.; FIDELIS, A.; SCHMIDT, I.; PIVELLO, V. Efeitos de altas temperaturas na germinação de sementes de capim-dourado (Syngonanthus nitens (Bong.) Ruhland, Eriocaulaceae): implicações para o manejo. Acta Botanica Brasilica, v. 26, n. 2, p.508-511, 2012. doi: 10.1590/S0102-33062012000200001

FIEDLER, N. C.; CANZIAN, W. P.; MAFIA, R. G.; RIBEIRO, G. A.; KRAUSE JUNIOR, J. Intensidade de queima de diferentes retardantes de fogo. Revista Árvore, v.39, n.4, 2015. http://dx.doi.org/10.1590/0100-67622015000400011

FIEDLER, N. C., RODRIGUES, T. O., MEDEIROS, M. B. Avaliação das condições de trabalho, treinamento, saúde e segurança de brigadistas de combate à incêndios florestais em unidades de conservação do Distrito federal - Estudo de caso. Revista Árvore, v.30, n.1, p.55-63, 2006. doi:10.1590/S0100-67622006000100001

FIEDLER, N. C.; AZEVEDO, I. N. C.; REZENDE, A. V.; MEDEIROS, M. B.; VENTUROILI, F. Efeito de incêndios florestais na estrutura e composição florística de uma área de cerrado sensu stricto na fazenda Água Limpa - DF. Revista Árvore, v.28, n. 1, p.129-138, 2004. doi: 10.1590/S0100-67622004000100001

INMET. Instituto Nacional de Meteorologia. Disponível em http://www.inmet.gov.br. Acessado em outubro de 2009.

LOURENÇO, L.; FERNANDES, S.; BENTO-GONÇALVES, A.; CASTRO, A.; NUNES, A.; VIEIRA, A. Causas de incêndios florestais em Portugal continental. Análise estatística da investigação efetuada no último quindênio (1996 a 2010). Cadernos de Geografia, n. 30/31, p. 61-80, 2012. http://hdl.handle.net/1822/25047

MEDEIROS, M. B.; MIRANDA, H. S. Mortalidade pós-fogo em espécies lenhosas de campo sujo submetido a três queimadas prescritas anuais Acta Botanica Brasilica, v. 19 , n. 3, p. 493-500, 2005. doi: 10.1590/S0102-33062005000300001

NOGUEIRA, G. S.; RIBEIRO, G. A.; RIBEIRO, C. A. A. S.; SILVA, E. P. Escolha de locais para instalação de torres de detecção de incêndio com auxílio do SIG. Revista Árvore, Viçosa-MG, v.26, n.3, p.363-369, 2002. doi: 10.1590/S010067622002000300001

PALERMO, A. C.; MIRANDA, H. S. Efeito do fogo na produção de frutos de Qualea parviflora MART. (Vochysiaceae) em Cerrado Sensu Stricto. Revista Árvore, v.36, 
n.4, p.685-693, 2012. doi: 10.1590/S0100-67622012000400001

RIBEIRO, M. N.; SANCHEZ, M.; PEDRONI, F.; PEIXOTO, K. S. Fogo e dinâmica da comunidade lenhosa em cerrado sentido restrito, Barra do Garças, Mato Grosso. Acta Botanica Brasilica, v. 26, n.1, p.203-217, 2012. doi: 10.1590/S010233062012000100001

SILVA, D. M.; LOIOLA, P. P.; ROSATTI, N. B.; SILVA, I. A.; CIANCIARUSO, M. V.; BATALHA, M. A. Os Efeitos dos Regimes de Fogo sobre a Vegetação de Cerrado no Parque Nacional das Emas, GO: Considerações para a Conservação da Diversidade. Biodiversidade Brasileira, v. 1, n. 2, p. 26-39, 2011.

SILVA, J. C.; FIEDLER, N. C.; RIBEIRO, G. A.; SILVA JUNIOR, M. C. Avaliação de brigadas de incêndios florestais e unidade de conservação. Revista Árvore, ViçosaMG, v.27, n.1, p.95-101, 2003. doi: 10.1590/S0100-67622003000100001

SISFOGO. Sistema Nacional de Informações Sobre Fogo in PREVFOGO - Centro Nacional de Prevenção e Combate aos Incêndios Florestais. Disponível em http://siscom.ibama.gov.br/sisfogo/publico.php. Acessado em outubro de 2009.

VALE, A. T.; ELIAS, P. S. Nível de proteção térmica da casca de quatro espécies lenhosas e a relação da arquitetura da casca com a transferência de calor. Ciência Florestal, v. 24, n. 4, p. 977-985, 2014. http://dx.doi.org/10.5902/1980509816611 


\section{Anexo}

Anexo 1 - Questionário aplicado aos funcionários participantes da brigada, proposto por SILVA et al. (2003).

\section{Questionário aplicado aos brigadistas}

1) Há quanto tempo você participa da brigada de prevenção e combate aos incêndios florestais?

2) Você se sente satisfeito em participar da brigada?

( ) $\operatorname{SIM}($ ) NÃO

3) Você já participou de algum curso de treinamento oferecido pelo Corpo de Bombeiros

( ) SIM ( ) NÃO outras instituições?

4) Você considera adequados os cursos oferecidos?

( ) SIM ( ) NÃO

5) Na sua opinião a brigada está preparada em termos de equipamentos e ferramentas para combater pequenos focos de incêndio? ( ) $\operatorname{SIM}($ ) NÃO

6) A brigada possui equipamentos de proteção individual para todos os brigadistas? ( ) $\operatorname{SIM}($ ) NÃO

7) Cite três trabalhos de prevenção realizados pela brigada

8) Na sua opinião existe necessidade de melhorias no sistema de prevenção e combate?

Quais? 
9) Como você avaliaria o trabalho de coordenação da brigada?

( ) Ótimo ( ) Bom ( ) Regular ( ) Ruim

10) Você acha necessário aumentar o número de brigadistas? ) NÃO 